scores of DAPOS $(p<0.05)$. Patients with high scores on DAPOS exhibited higher risk for worse pain-disability after follow-up. Additionally, patients with higher baseline scores on TSK $(>38)$ had a lower step count over time $(\mathrm{p}<0.05)$.

Conclusion Depressed mood and fear of movement affect the outcomes of disability, the level of physical activity and the pain intensity in patients with acute LBP.

\section{P2-463 USE OF SUBSTANCE AMONG RESIDENTS OF KARACHI: REASONS AND COSTS OF USING SUBSTANCES}

doi:10.1136/jech.2011.142976l.91

M Parveen, ${ }^{*}$ S Pyar Ali. Aga Khan University, Sindh, Pakistan

Introduction Use of substances (pan, chaalia, ghutka, niswar) is associated with serious health risks. In Pakistan most people use substances from early years of life which keeps them on risk of short life span. The aim of this study was to estimate the costs of using these substances and to understand the reasons for using substances. Methodology This was a cross-sectional study conducted in two residential colonies in Karachi, Pakistan during 2008-2009. Pre-coded structured questionnaire was administered to collect the data on socio demographics, use of substance, costs and reasons for use of substances. Results From 124 randomly selected residents, 107 (86\%) agreed to respond. All the selected participants were between the ages $10-71$ years (mean $\pm S D$ age $36.2 \pm 16.4$ ). Daily use of substances was significantly higher among males $(p<0.001)$. Further, the use was higher among adolescents than adults $(p<0.001)$ and interestingly less educated consumed less than high educated $(p=0.06)$. Males are

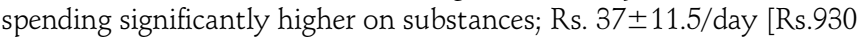
or (US\$13)/month] compared to females. Overall, $41 \%$ of the cost is spent on cigarettes followed by $27 \%$ on local ghutka. The main reasons for using substances were peer pressure, easy availability of substances, stress, liking of taste and to treat toothache.

Conclusion This study concluded that use of substances is higher among young males and they are spending substantial amount on those substances. To prevent this population, regular awareness campaigns may be held at community and school level so that, continuous re-enforcement make them to quit from using any substances.

\section{P2-464 INCIDENCE AND MAIN CAUSES OF SEVERE MATERNAL MORBIDITY IN SÃO LUÍS/MARANHÃO-BRAZIL: A LONGITUDINAL STUDY}

doi:10.1136/jech.2011.142976l.92

\begin{abstract}
${ }^{1}$ A P Moraes, ${ }^{1,2} \mathrm{~S}$ Barreto, ${ }^{1,2} \mathrm{~V}$ Passos, ${ }^{*}{ }^{3} \mathrm{P}$ Golino, ${ }^{4} \mathrm{~J}$ Costa, ${ }^{4} \mathrm{M}$ Vasconcelos. ${ }^{1}$ Public Health Postgraduate Program, Faculty of Medicine, Federal University of Minas Gerais, Belo Horizonte, Minas Gerais, Brazil; ${ }^{2}$ Faculty of Medicine, Federal University of Minas Gerais, Belo Horizonte, Minas Gerais, Brazil; ${ }^{3}$ Maternity Marly Sarney, São Luís, Maranhão, Brazil; ${ }^{4}$ Gynecology and Obstetrics Residence, Federal University of Maranhão, São Luís, Maranhão, Brazil
\end{abstract}

Introduction The evaluation of severe maternal morbidity has been used in the monitoring of maternal health. The objective of this study is to estimate its incidence and main causes in São LuísMaranhão, one of the poorest cities in Brazil.

Methods A prospective longitudinal study, carried out in two public high risk maternity clinics and two intensive care units (ICUs) of reference to obstetrical cases of the city. During the period of 1 March 2009 and 28 February 2010, all cases of severe maternal morbidity were identified following Mantel's and Waterstone's criteria. Socio-demographic characteristics and healthcare data of the extremely severe cases were compared to the less severe cases.
The Fisher, $\chi^{2}$, Student $t$, and Mann-Whitney tests were used for a statistical analysis, with significance levels of $<0.05$.

Results 127 cases of severe maternal morbidity among 8493 deliveries were identified, leading to an incidence of 15.0/1000 deliveries. 122 women were interviewed, five cases were lost (3.9\%). 121 cases fell under Waterstone's criteria and 29 under Mantel's criteria, corresponding to incidences of $14.1 / 1000$ and 3.4/1000 deliveries, respectively. These rates are lower than those described in the literature, possibly due to case loss. The main causes of morbidity were hypertension during pregnancy, more frequent in less severe cases $(p=0.001)$ and obstetrical haemorrhage, more common among extreme severe cases $(p=0.01)$.

Conclusion The obstetrical disorders are the main causes of severe maternal morbidity in São Luís/Maranhão. The investigation and monitoring of severe morbidity can contribute to improve the obstetrical assistance in the city.

\section{P2-465 REGIONAL VARIATION IN HISTOPATHOLOGY-SPECIFIC INCIDENCE OF INVASIVE CERVICAL CANCER AMONG PERUVIAN WOMEN}

doi:10.1136/jech.2011.142976l.93

${ }^{1} \mathrm{C}$ P Campbell, ${ }^{* 2} \mathrm{M}$ P Curado, ${ }^{1} \mathrm{~S}$ Harlow, ${ }^{1} \mathrm{~A}$ Soliman. ${ }^{1}$ Department of Epidemiology, School of Public Health, University of Michigan, Ann Arbor, Michigan, USA; ${ }^{2}$ Cancer Information Section, International Agency for Research on Cancer, Lyon, France

Introduction This study aimed to evaluate cervical cancer patterns in Peru by examining the variation in two common histopathologic types, squamous cell carcinoma (SCC) and adenocarcinoma (ADC), and analysing differences over time.

Methods Data on invasive cervical cancer incidence was obtained from three population-based cancer registries in Peru: Lima, Arequipa, and Trujillo. A cervical cancer-specific quality assessment was performed on each registry. Crude and age-specific incidence rates per 100000 were calculated for overall, SCC- and ADC-specific cervical cancers, and time trends analysed.

Results Lima and Trujillo demonstrated acceptable data quality; however, Arequipa was questionable. Incidence rates for overall cervical cancer were significantly different across registries: Arequipa (47.2), Trujillo (36.1), and Lima (18.9). Rates for SCC were significantly lower in Lima (14.0) as compared to Arequipa (29.7) and Trujillo (30.0). Rates for ADC did not differ significantly across registries. Time trend analyses showed significant declines in overall and SCC-specific rates in Trujillo. No other time trends were found. Age-specific analyses showed that young women (15-29 years) in Trujillo and Arequipa experienced significant increases in ADCspecific rates over time.

Conclusion Cancer registry data showed that overall and histopathology-specific cervical cancer incidence rates varied across regions of Peru, and over time. The use of cancer registry data proved to be an efficient method for evaluating cervical cancer incidence patterns in Peru. We suggest supplementing current screening methods with newer preventive methods to combat the rising incidence of $\mathrm{ADC}$ among young women in Peru.

\section{P2-466 AIR POLLUTION EFFECTS IN RESPIRATORY HEALTH IN SICK POPULATION: A MULTILEVEL STUDY IN BUCARAMANGA COLOMBIA}

doi:10.1136/jech.2011.142976l.94

1,2 L A Rodriguez, ${ }^{3} \mathrm{H}$ Castro, ${ }^{2} \mathrm{~J} J$ Rey. ${ }^{1}$ Universidad Industrial de Santander, Bucaramanga, Santander, Colombia; ${ }^{2}$ Observatorio de Salud Pública de Santander, 